\title{
Evaluation of Etiological, Clinical and Laboratory Findings in Infants with Prolonged Jaundice
}

\author{
Erhan Aygün ${ }^{1 *}$, Emine Yurdakul Ertürk ${ }^{2}$, Özden Aksu Sayman ${ }^{2}$ and Feyza Kübra Tiryaki ${ }^{3}$ \\ ${ }^{1}$ Division of Neonatology, Department of Pediatrics, Ordu University Training and Research Hospital, 52200 Ordu, Turkey \\ ${ }^{2}$ Department of Pediatrics, Ordu University Training and Research Hospital, 52200 Ordu, Turkey \\ ${ }^{3}$ Istanbul Medical School, Istanbul University, Millet Caddesi, Fatih, Istanbul, 34093, Turkey
}

*Corresponding author: Erhan Aygün, MD, Division of Neonatology, Department of Pediatrics, Ordu University Training and

Research Hospital, 52200 Ordu, Turkey

\begin{tabular}{l}
\hline ARTICLE INFO \\
\hline Received: 㓞 October 30, 2020 \\
Published: November 09, 2020 \\
\hline
\end{tabular}

Citation: Erhan Aygün, Emine Yurdakul Ertürk, Özden Aksu Sayman, Feyza Kübra Tiryaki. Evaluation of Etiological, Clinical and Laboratory Findings in Infants with Prolonged Jaundice. Biomed J Sci \& Tech Res 31(5)-2020. BJSTR. MS.ID.005151.

Keywords: Neonatal Hyperbilirubinemia; Breastfeeding

\begin{abstract}
Objectives: Prolonged jaundice is a common condition among neonates. İt is defined as persisting hyperbilirubinemia after the 14th day following birth for term babies and after the 21st day for premature babies with serum bilirubin level higher than $5 \mathrm{mg} / \mathrm{dL}$. Prolonged unconjugated hyperbilirubinemia may be associated with some pathological conditions. We aimed to evaluate the etiological, clinical and laboratory findings of babies with prolonged jaundice.
\end{abstract}

Methods: This descriptive cross-sectional study included 90 infants with prolonged jaundice in the pediatric outpatient clinic of Ordu University Training and Research Hospital between 1 January 2015 and 1 October 2020. Demographic characteristics, physical examination and laboratory findings of the babies were collected and analyzed to determine the etiology of neonatal hyperbilirubinemia.

Results: In total 90 infants with prolonged jaundice were presented in this study, including 50 male and 40 female neonates. The most common causes of prolonged neonatal jaundice were breastfeeding, $\mathrm{Rh}$ or $\mathrm{ABO}$ incompatibility, and urinary tract infection $73 \%, 13 \%$ and $8 \%$ of neonates, respectively.

Conclusion: Breast milk jaundice is the most common cause of prolonged jaundice in infants. Although there are some explanations for breast milk jaundice, the exact mechanism leading to breast milk jaundice is not clear. Other reasons that may affect the infants later in life should be investigated in a short time.

\section{Introduction}

Prolonged jaundice is defined as persisting hyperbilirubinemia after the $14^{\text {th }}$ day following birth for term babies and after the 21 st day for premature babies with serum bilirubin level higher than $5 \mathrm{mg} / \mathrm{dL}[1,2]$. It can occur in $2-15 \%$ of all newborns and up to $40 \%$ in breastfed infants [3]. It is essential to determine the etiology of jaundice caused by unconjugated (indirect) or conjugated (direct) hyperbilirubinemia. Prolonged unconjugated hyperbilirubinemia may be associated with some pathological conditions such as breastfeeding, hemolytic diseases (Rh or AB0 incompatibility or glucose-6-phosphate dehydrogenase (G6PD) deficiency), congenital hypothyroidism, urinary infection, Crigler-Najjar or Gilbert syndromes [4,5]. However, the etiology of prolonged jaundice in infants mostly remained unidentified and reported in association with breastfeeding in the literature [6,7]. After excluding the known etiologies, the majority of prolonged jaundice is defined as breast milk jaundice [1]. Tests performed to determine the underlying cause and failure to determine the etiology cause anxiety for both families and physicians. Therefore, we aimed to evaluate the etiological, clinical and laboratory findings of babies with prolonged jaundice. 


\section{Materials and Methods}

\section{Study Design}

This descriptive cross-sectional study included 90 infants with prolonged jaundice in the pediatric outpatient clinic of Ordu University Training and Research Hospital between 1 January 2015 and 1 October 2020. Serum bilirubin level higher than $5 \mathrm{mg} / \mathrm{dl}$ after the $14^{\text {th }}$ day following birth for term babies and after the 21 st day for premature babies was defined as prolonged jaundice [1]. The exclusion criteria were the following: Gestational age $<35$ weeks, acute-life threatening event, need for neonatal intensive care unit, chromosomal or congenital anomalies, direct bilirubin level $>20 \%$ of total bilirubin or $>2 \mathrm{mg} / \mathrm{dL}$. Prenatal, natal, and postnatal characteristics of the infants were investigated. In prenatal history, preeclampsia, eclampsia, hypertension, and hypothyroidism were evaluated in the mother. Date of birth, birth-weight, gestational age, gender, type of delivery, premature rupture of membranes, and history of birth with meconium were recorded in natal history.

Parental consanguinity, sibling numbers, and jaundice history in previous siblings were asked. The time of onset of jaundice, history of previous phototherapy, presence of cephalohematoma in the physical exam, hospitalization history, and feeding status were recorded in postnatal history. Problems encountered during clinical follow-up and treatments applied were determined.

Laboratory evaluations were included the mother-baby blood group, direct Coombs test, reticulocyte count, total bilirubin level at the time of diagnosis with prolonged jaundice, complete blood count, reducing substance in urine, G6PD enzyme level, and Thyroid Function Tests (TSH, fT4). Among the biochemical parameters, serum Aspartate Aminotransferase (AST), Alanine Aminotransferase (ALT), and Gamma-Glutamyl Transferase (GGT) levels were evaluated. After microscopic evaluation, urine culture results were obtained with bladder catheter for those with suspected infection in the bag urine culture. In cases where leukocytes were seen in five or more in each area on microscopic examination of urine, and the growth of $\geq 10.000 \mathrm{CFU} / \mathrm{mL}$ microorganisms in urine culture was accepted as UTI, and appropriate antibiotic therapy was administered. In patients with positive reducing substance in urine, urine sugar chromatography was planned. Abdominal Ultrasonography (USG) was performed to evaluate the liver and bile ducts.

\section{Data Analysis}

Statistical analysis was performed using IBM SPSS 21.0. Shapiro-Wilk test was used to assess if the variables were normally distributed. The results of descriptive statistics were presented for the normally distributed variables as mean \pm SD (Standard Deviation) and for non-normally distributed variables as median. Chi-square test was used for categorical data in the comparison between groups. $p<0.05$ was considered as statistically significant.

\section{Results}

The demographic characteristics of 90 infants with prolonged jaundice were presented in Table 1. In antenatal history, five mothers
(5.5\%) had hypertension, two $(2.2 \%)$ had preeclampsia, seven $(7.7 \%)$ had gestational diabetes, and six $(6.6 \%)$ had urinary tract infection. Anti-D immunoglobulin (Rhogam $®$ ) was administered to two mothers after giving birth. Term, early term, and late preterm infants made up $40 \%, 50 \%$, and $10 \%$ of the infants, respectively, and all infants were appropriate gestational age. There was no difference between these infants except their birth weights and gestational ages $(p>0.05)$. One infant had cephalohematoma. There was no infant taking phenobarbital. Ten infants' (9\%) urine were tested for reducing substances, and one had a positive result. Urine from the infant with a positive result was examined for urine sugar by chromatography, and the result was normal. Serum vitamin B12 levels were examined in 20 infants with a lack of head-lifting, neurological symptoms such as poor smiling and eye-tracking, and maternal vitamin B12 deficiency.

Table 1: Demographic characteristics of infants with prolonged jaundice.

\begin{tabular}{|c|c|}
\hline Characteristic & Result \\
\hline Birth weight (g) (mean干 SD) & $3100 \pm 480(2400-4050)$ \\
\hline $\begin{array}{c}\text { Gestational age (weeks) } \\
\text { Term, n (\%) } \\
\text { Early term, n (\%) } \\
\text { Late preterm, n (\%) }\end{array}$ & $\begin{array}{c}38 \pm 1.6(35-41) \\
36(40 \%) \\
45(50 \%) \\
9(10 \%)\end{array}$ \\
\hline $\begin{array}{c}\text { Gender, n (\%) } \\
\text { Girl } \\
\text { Boy }\end{array}$ & $\begin{array}{l}40(44.44 \%) \\
50(55.55 \%)\end{array}$ \\
\hline $\begin{array}{c}\text { Route of delivery, } \mathrm{n}(\%) \\
\text { Vaginal } \\
\text { Cesarean }\end{array}$ & $\begin{array}{l}42(46.66 \%) \\
48(53.33 \%)\end{array}$ \\
\hline $\begin{array}{l}\text { Feeding mode, } \mathrm{n}(\%) \\
\text { Breastfeed } \\
\text { Breastfeed+Formula } \\
\text { Formula }\end{array}$ & $\begin{array}{c}77(85.55 \%) \\
10(11.11 \%) \\
3(3.33 \%)\end{array}$ \\
\hline $\begin{array}{l}\text { Age at diagnosis (days) (median) } \\
\text { Sibling, n (\%) } \\
\text { Present } \\
\text { Absent }\end{array}$ & $\begin{array}{c}19(14-58) \\
38(42.22 \%) \\
52(57.77 \%)\end{array}$ \\
\hline $\begin{array}{l}\text { History of Jaundice in Siblings, } \mathrm{n} \\
\qquad \begin{array}{l}(\%) \\
\text { Yes } \\
\text { No }\end{array}\end{array}$ & $\begin{array}{l}28(31.11 \%) \\
62(68.88 \%)\end{array}$ \\
\hline $\begin{array}{l}\text { History of Phototherapy for } \\
\text { Jaundice } \\
\text { Yes } \\
\text { No }\end{array}$ & $\begin{array}{l}44(48.88 \%) \\
46(51.11 \%)\end{array}$ \\
\hline $\begin{array}{l}\text { History of Phototherapy in Siblings } \\
\qquad \begin{array}{l}\text { Yes } \\
\text { No }\end{array}\end{array}$ & $\begin{array}{l}10(11.11 \%) \\
77(85.55 \%)\end{array}$ \\
\hline
\end{tabular}

Eighteen infants out of 20 had low vitamin B12 levels. Rh and ABO incompatibility between mother and baby was 3.33\% (n: 3) and $10 \%$ (n: 9), respectively. Subgroup incompatibility could not be 
evaluated. Three infants with Rh incompatibility who had a positive direct Coombs test were received phototherapy, but exchange transfusion was not done. The results of five babies screened for TORCH were negative. None of the 50 cases evaluated by abdominal USG had pathology in the liver or bile ducts. Five patients had unilateral minimal pelvicaliectasis, one had hydronephrosis, and one had adrenal hemorrhage. None of our cases needed repeat phototherapy. The etiologic distribution of infants with prolonged jaundice was shown in Table 2. Laboratory results of infants were given in Table 3. The etiologic distribution of prolonged jaundice in infants with and without phototherapy history was shown in Table 4. The history of phototherapy was significantly higher in infants diagnosed with isoimmunization ( $\mathrm{Rh}$ or $\mathrm{ABO}$ Incompatibility) $(\mathrm{p}<0.001)$.

Table 2: Etiologic distribution of infants with prolonged jaundice.

\begin{tabular}{|c|c|}
\hline Isoimmunization (Rh or ABO Incompatibility) & $\mathbf{1 2} \mathbf{( 1 3 . 3 3 \% )}$ \\
\hline Congenital Hypothyroidy & $1(1.11 \%)$ \\
\hline Glucose-6-Phosphate Dehydrogenase Deficiency & $1(1.11 \%)$ \\
\hline Hereditary Spherocytosis & $1(1.11 \%)$ \\
\hline Urinary Tract Infection & $8(8.88 \%)$ \\
\hline Cephalohematoma & $1(1.1 \%)$ \\
\hline Adrenal Hemorrhage & $1(1.1 \%)$ \\
\hline No etiologic factor determined (breastfeeding) & $66(73.33 \%)$ \\
\hline
\end{tabular}

Table 3: Laboratory results of infants with prolonged jaundice.

\begin{tabular}{|c|c|}
\hline Test & Result \\
\hline Hemoglobin, g/dL & $15 \pm 2.6$ \\
\hline Hematocrit, $\%$ & $44 \pm 6.6$ \\
\hline Leukocyte, $/ \mathrm{mm}^{3}$ & $8800 \pm 2400$ \\
\hline Platelet, $/ \mathrm{mm}^{3}$ & $320.200 \pm 110.000$ \\
\hline Total bilirubin, $\mathrm{mg} / \mathrm{dL}$ & $13.2 \pm 3$ \\
\hline AST, IU/L & $32 \pm 18$ \\
\hline ALT, IU/L & $18 \pm 12$ \\
\hline GGT, IU/L & $124 \pm 58$ \\
\hline ALP, IU/L & $225 \pm 118$ \\
\hline Albumin, $\mathrm{mg} / \mathrm{dL}$ & $3.1 \pm 0.5$ \\
\hline TSH, $\mu \mathrm{IU} / \mathrm{mL}$ & $4.4 \pm 3.8$ \\
\hline T4, ng/dL & $1.22 \pm 0.18$ \\
\hline Vitamin B12, ng/L & $168 \pm 120$ \\
\hline
\end{tabular}

*Note: Data are shown as mean \pm SD. AST: Aspartate aminotransferase ALP: Alkaline phosphatase Gamma, GT: Gamma glutaryl transferase TSH: Thyroid-stimulating hormone, T4: Thyroxine.

Table 4: Etiologic distribution of prolonged jaundice in infants with and without phototherapy history.

\begin{tabular}{|c|c|c|c|}
\hline Characteristic & $\begin{array}{c}\text { Receiving } \\
\text { phototherapy } \\
(\mathbf{n = 4 4 )}\end{array}$ & $\begin{array}{c}\text { Not receiving } \\
\text { phototherapy } \\
(\mathbf{n = 4 6 )}\end{array}$ & $\mathbf{p}$ \\
\hline $\begin{array}{c}\text { Isoimmunization } \\
\text { (Rh or ABO } \\
\text { Incompatibility) }\end{array}$ & 12 & 0 & 0.011 \\
\hline
\end{tabular}

\begin{tabular}{|c|c|c|c|}
\hline $\begin{array}{c}\text { Other } \\
\text { (UTI, } \\
\text { cephalohematoma, } \\
\text { congenital } \\
\text { hypothyroidy, G6PD } \\
\text { deficiency, HS) }\end{array}$ & 7 & 5 & 0.77 \\
\hline $\begin{array}{c}\text { No etiologic factor } \\
\text { determined }\end{array}$ & 25 & 41 & 0.56 \\
\hline
\end{tabular}

*Note: UTI: Urinary tract infection G6PD: Glucose-6-phosphate dehydrogenase HS: hereditary spherocytosis.

\section{Discussion}

Under the results of this study, the most common causes of prolonged neonatal jaundice are breastfeeding, $\mathrm{Rh}$ or $\mathrm{ABO}$ incompatibility, and UTI, which is compatible with the findings of previous studies conducted in this regard [3,8]. According to many studies in the literature, since no specific etiologies could be confirmed in most infants diagnosed with prolonged unconjugated hyperbilirubinemia, breast milk jaundice is the main cause of prolonged jaundice. In the present study, the etiologic factor was breast milk jaundice in $73.3 \%$ of infants with prolonged jaundice [3,8-10]. Beta-glucuronidase, Pregnan-3a, 20b-diol, free fatty acids, and genetic causes (UGT1A1) were blamed for breast milk jaundice [11]. Due to maternal vitamin B12 deficiency, lack of head-lifting, and neurologic symptoms such as poor smiling and eye-tracking, serum vitamin B12 levels were examined in cases with prolonged jaundice of unidentified etiology. 18 infants out of 20 had low vitamin B12 levels. There is no study in the literature showing whether there is an association between prolonged jaundice and vitamin B12 deficiency.

Vitamin B12 is a crucial factor for DNA synthesis, acting as a cofactor for key enzymatic reactions. The deficiency of Vitamin B12 leads to megaloblastic anemia due to ineffective erythropoiesis. It is suggested that ineffective erythropoiesis may cause immature erythrocyte formation that is lysed within the bone marrow. It results in releases of excess quantities of biliverdin, which is ultimately converted to indirect bilirubin leading to unconjugated hyperbilirubinemia. In our study, we could not make further comments, since the number of cases whose serum vitamin B12 levels were checked was very low and there was no control group. Extensive prospective studies are needed to confirm this.

It should be reminded to the family that although breastfeeding is the most common cause of prolonged jaundice, breastfeeding should not be interrupted. In our study, Urinary Tract Infection (UTI) was detected in $8.8 \%$ of infants with prolonged jaundice. UTI increases bilirubin load by causing hemolysis in erythrocytes, and causes hyperbilirubinemia by decreasing conjugation in the liver, and decreasing excretion of bilirubin [11]. In some studies, the prevalence of UTI in prolonged jaundice was as low as 5-10\%, while it was found to be higher as $15-36 \%$ in other studies $[1,8,12-17]$. Different incidence of UTI may be related to urine culture techniques. In some studies, false positive-results may have been found because 
the diagnosis was made only by bag urine culture. Although the prevalence of UTI was different in the literature, prolonged jaundice may be the only finding in infants with UTI. Thus, the microscopic examination and culture of urine should be requested in these infants. For asymptomatic infants with prolonged jaundice whose bag urine culture was positive, confirmation with urine culture obtained by suprapubic aspiration or bladder catheter is recommended [18]. Early diagnosis and treatment of these infants will reduce the risk of urinary tract infections and its complications in the long-term. In the literature, the prevalence of hemolysis due to blood group incompatibilities with a positive Coombs test was found to be $5-13 \%$ in the etiology of prolonged jaundice.

Likely, in our study, it was \% 13.33 (n: 12) [8,19]. Persistent hemolysis in blood incompatibilities, which is a major risk factor for jaundice, can be explained as the reason for this. In our study, 48.88\% (n: 44) of cases with prolonged jaundice were previously received phototherapy. The history of phototherapy was significantly higher in infants diagnosed with isoimmunization (Rh or ABO Incompatibility). The cause of prolonged jaundice can be explained by bilirubin generated by persistent hemolysis. The prevalence of G6PD enzyme deficiency was reported as 6-13\% in studies conducted in Turkey [19-21]. It was 1.1\% (n: 1) in our study. This can be explained by regional differences. The prevalence of congenital hypothyroidism in infants with prolonged jaundice was reported as $6-8 \%$ in the literature [8,9]. It was found to be $1.1 \%$ (n: 1) in our study. This difference can be explained by monitoring maternal thyroid diseases during pregnancy, also checking and monitoring newborns' TSH levels during newborn screening programs.

\section{Conclusion}

Breast milk jaundice is the most common cause of prolonged jaundice in infants. Although there are some explanations for breast milk jaundice, the exact mechanism leading to breast milk jaundice is not clear. Other reasons that may affect the infants later in life should be investigated in a short time.

\section{Conflict of Interests}

It is not declared by the authors.

\section{Ethical Approval}

Ordu University Ethics Committee on 20 August 2020 approved the study.

\section{Funding}

The authors received no financial support for the research and/ or authorship of this article.

\section{Informed Consent}

Written informed consent was not obtained as the study is retrospective. But the Local Ethics Committee approved the current study (20.08.2020/ 2020-162).

\section{References}

1. Çoban A, Türkmen MK, Gürsoy T (2018) Turkish Neonatal Society guideline to the approach, follow-up, and treatment of neonatal jaundice. Turk Pediatri Ars 53(Suppl 1): S172-S179.

2. Kaplan M, Merlob P, Regev R (2008) Israel guidelines for the management of neonatal hyperbilirubinemia and prevention of kernicterus. J Perinatol 28(6): 389-397.

3. Hannam S, McDonnell M, Rennie JM (2000) Investigation of prolonged neonatal jaundice. Acta Paediatr 89(6): 694-697.

4. (2004) Management of hyperbilirubinemia in the newborn infant 35 or more weeks of gestation. Pediatrics 114(1): 297-316.

5. Hussein M, Howard ER, Mieli Vergani G (1991) Jaundice at 14 days of age: exclude biliary atresia. Arch Dis Child 66(10): 1177-1179.

6. Siu SL, Chan LW, Kwong AN (2018) Clinical and biochemical characteristics of infants with prolonged neonatal jaundice. Hong Kong Med J 24(3): 270-276.

7. Çetinkaya M OzH, Köksal N, Akacı O (2008) The Distribution of Etiology in Newborns with Prolonged Jaundice. The Journal of Current Pediatrics 6: 99-103.

8. Najati N, Gharebaghi MM, Mortazavi F (2010) Underlying etiologies of prolonged icterus in neonates. Pak J Biol Sci. 13(14): 711-714.

9. Sabzehei MK BB, Gohari Z, Bazmamoun H (2015) Etiologies of prolonged unconjugated hyperbilirubinemia in neonates admitted to neonatal wards. Iranian Journal of Neonatology IJN 6(4): 37-42.

10. Maisels MJ, Clune S, Coleman K (2014) The natural history of jaundice in predominantly breastfed infants. Pediatrics 134(2): e340-345.

11. Madan A MJ, Stevenson DK (2015) Neonatal hiperbilirubinemia: penyunting; 2015 Edisi ke-8. In Taeusch HW BR, Gleason CA(Eds.) Avery's disease of the newborn.

12. Ullah S, Rahman K, Hedayati M (2016) Hyperbilirubinemia in Neonates: Types, Causes, Clinical Examinations, Preventive Measures and Treatments: A Narrative Review Article. Iran J Public Health 45(5): 558568.

13. Bilgen $H$, Ozek E, Unver $T$ (2006) Urinary tract infection and hyperbilirubinemia. Turk J Pediatr 48(1): 51-55.

14. GC M (2006) Fanaroff and Martin's neonatal perinatal medicine diseases of the fetus and infant Arch. In GC M (Eds.), (11 ${ }^{\text {th }}$ Edn.), Dis. Child. Fetal Neonatal 91(2): 2157.

15. Kleigman RM BR JH, Stanton BF (2008) Nelson Textbook of Pediatrics. The fetus and the neonatal infant: Jaundice and hyperbilirubinemia in the newborn. In Kleigman RM BR JH, Stanton BF (Eds.), (18 Edn.), WB Saunders Company, Philadelphia.

16. Ahlfors CE, Wennberg RP (2004) Bilirubin-albumin binding and neonatal jaundice. Semin Perinatol. 28(5): 334-339.

17. Malla T, Sathian B, Karmacharya Malla K (2016) Urinary Tract Infection in Asymptomatic Newborns with Prolonged Unconjugated Hyperbilirubunemia: A Hospital based Observational study from Western Region of Nepal. Kathmandu Univ Med J (KUMJ) 14(53): 41-46.

18. Stocker R, McDonagh AF, Glazer AN (1990) Antioxidant activities of bile pigments: biliverdin and bilirubin. Methods Enzymol 186: 301-309.

19. Andre M, Day AS (2016) Causes of prolonged jaundice in infancy: 3-year experience in a tertiary paediatric centre. N Z Med J 129(1429): 14-21.

20. Turan Y (2006) Prevalence of erythrocyte glucose-6-phosphate dehydrogenase (G6PD) deficiency in the population of western Turkey. Arch Med Res 37(7): 880-882.

21. Albayrak C, Albayrak D (2015) Red cell glucose 6-phosphate dehydrogenase deficiency in the northern region of Turkey: is G6PD deficiency exclusively a male disease? Pediatr Hematol Oncol 32(2): 8591. 
ISSN: 2574-1241

DOI: 10.26717/BJSTR.2020.31.005151

Erhan Aygün. Biomed J Sci \& Tech Res

(C) This work is licensed under Creative

Submission Link: https://biomedres.us/submit-manuscript.php

$\begin{array}{ll}\text { BIOMEDICAL } & \text { Assets of Publishing with us } \\ \text { RESEARCHES } & \text { - Global archiving of articles } \\ \text { - Immediate, unrestricted online access }\end{array}$

